九州大学学術情報リポジトリ

Kyushu University Institutional Repository

Development of Myanmar strain of Cotesia vestalis (Hymenoptera: Braconidae) on Its Host Plutella xylostella (Lepidoptera: Plutellae) at Different Temperatures

Htwe, Ah Nge

Institute of Biological Control, Graduate School of Bioresource and Environmental Sciences, Kyushu University

Takagi, Masami

Faculty of Agriculture, Kyushu University

Takasu, Kenj i

Faculty of Agriculture, Kyushu University

https://doi.org/10.5109/12855

出版情報: 九州大学大学院農学研究院紀要. 53 (2)，pp.441-446，2008-10-28. Faculty of Agriculture, Kyushu University

バージョン：

権利関係 : 


\title{
Development of Myanmar strain of Cotesia vestalis (Hymenoptera: Braconidae) on Its Host Plutella xylostella (Lepidoptera: Plutellae) at Different Temperatures
}

\author{
Ah Nge HTWE ${ }^{1}$, Masami TAKAGI ${ }^{2}$ and Keiji TAKASU ${ }^{2}$
}

(Received June 27, 2008 and accepted July 16, 2008)

\begin{abstract}
The effect of seven constant temperatures on the development of the Myanmar strain of Cotesia vestalis, (Haliday), a larval parasitoid of diamondback moth Plutella xylostella (L.) was studied in the laboratory. Developmental times for immature stages were inversely proportional to temperature between 15 and $33^{\circ} \mathrm{C}$ but increased at $35^{\circ} \mathrm{C}$. Total developmental times from egg to adult emergence decreased from 63.7 to $9.4 \mathrm{~d}$ for temperatures from 15 to $33^{\circ} \mathrm{C}$, with pupae requiring less time for development than the combined egg and larva stage. Both linear and nonlinear (Logan equation VI) models provided a reliable fit of development rates versus temperature for all immature stages. The lower developmental thresholds that were estimated from linear regression equations for the egg to pupa, pupa to adult, and total combined immature stages were $8.9,10.1$, and $9.4^{\circ} \mathrm{C}$, respectively. The degree-day accumulation was calculated as 200 DD for development from egg to adult emergence. By fitting the nonlinear models to the data, the upper and optimal temperatures for egg to pupa, pupa to adult and total development stages were calculated as 38.2 and $35.0,35.0$ and $31.8,30.5$ and $31.3^{\circ} \mathrm{C}$, respectively. These data are useful for predicting population dynamics of $C$. vestalis under field conditions.
\end{abstract}

\section{INTRODUCTION}

The diamondback moth (DBM), Plutella xylostella (Linnaeus) (Lepidoptera: Plutellidae), is a serious pest of economically important cruciferous crops worldwide (Abro et al., 1992, Talekar and Shelton, 1993; Reddy et al., 2004 and Shelton, 2004). It is a major pest of cabbage, cauliflower and other cultivated crucifers and severe infestations are found in the main vegetable growing areas in Myanmar (Morris and Waterhouse, 2001; Maung and Morris 2001; Maung N, 2002). Although insecticides have been often used to control DBM, this pest has been developing resistance to many different insecticides (Shelton et al., 1993 and Sarfraz and Keddie, 2005). Biological control using parasitic wasps has also been attempted because biological control is more environmentally sound pest management approach (Talekar and Shelton, 1993). Although over 130 species of parasitoids have been recorded worldwide attacking various developmental stages of DBM, of these, most control worldwide is achieved by relatively few hymenopteran species belonging to the ichneumonid genera Diadegma and Diadromus, the braconid genera Microplitis and Cotesia, and the eulophid genus Oomyzus (Sarfraz et al., 2005).

Cotesia vestalis (Haliday) (Hymenoptera: Braconidae), commonly called Cotesia (or formerly Apanteles) plutellae (Kurdjumov), but now should be referred to as $C$. vestalis (Shaw, 2003) is a solitary endolarval parasitoid of DBM (Talekar and Yang, 1993; Noda et al., 1996; Kawaguchi and Tanaka, 1999). This parasitoid is distributed worldwide (Lim, 1986;

\footnotetext{
Institute of Biological Control, Graduate School of Bioresource and Environmental Sciences, Kyushu University, Fukuoka 812-8581, Japan

${ }^{2}$ Faculty of Agriculture, Kyushu University, Fukuoka 812-8581, Japan

* Corresponding author (E-mail: mtakagi@grt.kyushu-u.ac.jp)
}

Waterhouse and Norris, 1987; Talekar and Shelton, 1993; Talekar and Yang, 1993). Cotesia vestalis has been used in biological control programs of DBM in several countries because of its resistance against insecticides (Waterhouse and Norris, 1987; Fitton and Walker 1992). In Southeast Asia, C. vestalis is the only parasitoid known to survive the hot and humid climate of the lowlands (Verkerk and Wright, 1997).

Biological control, whether using the introduction, conservation or augmentation approaches, is facilitated when the climatic responses of biocontrol agents are known, especially responses to temperature (Royl et al., 2002). The development rate of an insect under natural conditions is largely determined by temperature (Liu et $a l ., 2002)$ and the temperature is a critical abiotic factor influencing the dynamics of insects (Roy et al., 2002). Complementary studies on development rates at different temperatures and the estimation of thermal requirements are useful for enhancing the efficiencies of biological control strategies. In biological control, details concerning such responses and estimation of the temperature thresholds and thermal constant for development of natural enemies can contribute substantially to the selection of the most suitable natural enemy to be used at different environmental conditions (Obrycki and Kring, 1998; Roy et al., 2002).

In Myanmar, native species of $C$. vestalis has been found to be a promising bio-control agent for diamondback moth and the effective release percentage is 50 to 70 percent (Thwin, 2001). But no information is available for temperature effect on development of $C$. vestalis in Myanmar. The study was conducted to observe the effect of different temperature, and to determine the optimal temperature rang for development of Myanmar strain of $C$. vestalis. 


\section{MATERIALS AND METHODS}

Plutella xylostella larvae were obtained from a stock culture maintained at Kyushu University. The laboratory colony of DBM was originated from field collected larvae and pupae and maintained on artificial diet (Htwe et al., in preparation). The culture of $C$. vestalis was established from cocoons and parasitized DBM larvae collected from cabbage fields in TadarOo City, Mandalay Township, Myanmar. The parasitoid was maintained on DBM larvae fed on artificial diet. Male and female $C$. vestalis was allowed to mate in a plexiglass cage $(30 \times 30 \times 30 \mathrm{~cm})$, one side of which had slide door $(13 \mathrm{~cm} \times 13 \mathrm{~cm})$ at the center, and two other sides of which were covered with fine nylon mesh, at $25^{\circ} \mathrm{C}$ and 16L; 8D. One to two day old mated female were used in this experiment. Individual $C$. vestalis female were first allowed to antennate frass of DBM larvae for 10s to stimulate their oviposition behavior. Second instar DBM larvae were exposed individually to each female. Parasitization was done in $25^{\circ} \mathrm{C}$ climatic condition room. After hosts were stung by $C$. vestalis, the stung hosts were kept in 10 larvae/petri dish ( $9 \mathrm{~cm}$ in diameter) containing artificial diet at different temperatures of 13, 15, $20,25,30,33,35 \pm 0.5^{\circ} \mathrm{C}$ (at $16 \mathrm{~L}$ : 8D). Total of six replicate and sixty larvae were done for each tested temperature. Parasitized larvae were checked everyday and the diets were renewed everyday. The parasitized larvae were maintained at the test temperature until emergence of adult parasitoids or host moths. After parasitoid larvae emerge and span cocoons, cocoons were collected and placed individually in small vial until adult emergence. Emergence of the parasitoid adults was checked everyday. The development time from egg to pupa and from pupa to adult emergence, and total development time were recorded.

\section{Statistical Analysis}

The effect of temperature $\left(13-33^{\circ} \mathrm{C}\right)$ on development time was analyzed by one-way analysis of variance (ANOVA). The means were separated by Tukey's honestly significant difference (HSD) test (SAS Institute 1998). The effect of temperature on the development rate of various stages (i.e., egg + larva, pupa and total development) was tested by linear regression using the model $\mathrm{Y}=\mathrm{bX}+\mathrm{a}$, where $\mathrm{Y}$ is developmental rate (1/developmental time), $\mathrm{X}$ is temperature, and $\mathrm{a}$ and $\mathrm{b}$ are the regression parameters obtained from the regression. The lower developmental thresholds $\left(\mathrm{T}_{0}\right)$ and the thermal constant (DD) requirement were estimated using the parameters: $\mathrm{T}_{0}=-\mathrm{a} / \mathrm{b}$ and $\mathrm{DD}=1 / \mathrm{b}$ (Campbell et al. 1974). Estimation of constants was based only on data obtained at $13-33^{\circ} \mathrm{C}$. The relationships between temperature $\left(13-35^{\circ} \mathrm{C}\right)$ and rate of development were also fitted by the nonlinear Logan model VI (Logan et al., 1976).

$$
\begin{aligned}
\mathrm{Y}= & \mathrm{P}_{1} \times\left\{\exp \left[\mathrm{P}_{2} \times\left(\mathrm{X}-\mathrm{T}_{0}\right)\right]-\exp \left[\mathrm{P}_{2} \times\left(\mathrm{T}_{\max }-\mathrm{T}_{0}\right)\right.\right. \\
& \left.\left.-\mathrm{P}_{3} \times\left(\mathrm{T}_{\max }-\mathrm{X}\right)\right]\right\}
\end{aligned}
$$

where $\mathrm{X}$ is the temperature, $\mathrm{T}_{0}$ is the lower developmental threshold, $\mathrm{T}_{\max }$ is the upper (lethal) temperature threshold, $\mathrm{P}_{1}, \mathrm{P}_{2}$ and $\mathrm{P}_{3}$ are coefficients. The optimum temperature for development was calculated after setting the first derivative of the Logan equation equal to zero. $\mathrm{T}_{\max }$ was estimated with Logan equation by QuasiNewton curve fit using MacCurveFit version 1.5 (Kevin Raner Software, Mt. Waverley, Australia).

\section{RESULTS}

Developmental time for C. vestalis at different temperatures is summarized in Table 1. Cotesia vestalis completed its development on $P$. xylostella at all tested temperatures except $35^{\circ} \mathrm{C}$. Although some larvae reached to pupa stage, no pupae succeeded in completing development at $35^{\circ} \mathrm{C}$. The duration of egg + larva stage decreased significantly as the temperature increased from 13 to $33^{\circ} \mathrm{C}(\mathrm{P}<0.0001)$. The duration of egg + larva stage varied from $37.3 \mathrm{~d}$ at $13{ }^{\circ} \mathrm{C}$ to $5.9 \mathrm{~d}$ at 30 and $33^{\circ} \mathrm{C}$ (Table 1). The duration of pupa stage and total duration from egg to adult were also decreased significantly as the temperature increased from 13 to $33^{\circ} \mathrm{C}(\mathrm{P}<0.0001)$. Pupa developmental time varied from $26.4 \mathrm{~d}$ at $13{ }^{\circ} \mathrm{C}$ to $3.5 \mathrm{~d}$ at $33^{\circ} \mathrm{C}$. Total developmental time from egg to adult emergence declined from $63.7 \mathrm{~d}$ at $13{ }^{\circ} \mathrm{C}$ to $9.4 \mathrm{~d}$ at $33^{\circ} \mathrm{C}$. There was no significant difference in duration of egg + larva stage and pupa stage as well as total development time from egg to adult emergence at 30 and $33{ }^{\circ} \mathrm{C}$ $(\mathrm{P}>0.05)$. The shortest total developmental time was $9.4 \mathrm{~d}$ at $33{ }^{\circ} \mathrm{C}$ and it was not significantly difference from

Table 1. Developmental times (days) of C.vestalis at different constant temperatures

\begin{tabular}{ccccc}
\hline \multirow{2}{*}{$\begin{array}{c}\text { Temperature } \\
{ }^{\circ} \mathrm{C}\end{array}$} & $\begin{array}{c}\text { No. of insect } \\
\text { observed }\end{array}$ & Egg + larva & Pupa & Total Development \\
\cline { 3 - 5 } & 25 & $37.3 \pm 0.45 \mathrm{a}$ & $26.4 \pm 0.34 \mathrm{a}$ & $63.7 \pm 0.46 \mathrm{a}$ \\
13 & 41 & $23.6 \pm 0.19 \mathrm{~b}$ & $17.4 \pm 0.21 \mathrm{~b}$ & $41.0 \pm 0.32 \mathrm{~b}$ \\
15 & 45 & $11.87 \pm 0.14 \mathrm{c}$ & $7.8 \pm 0.11 \mathrm{c}$ & $19.6 \pm 0.16 \mathrm{c}$ \\
20 & 50 & $7.7 \pm 0.13 \mathrm{~d}$ & $4.8 \pm 0.08 \mathrm{~d}$ & $12.5 \pm 0.12 \mathrm{~d}$ \\
25 & 46 & $5.9 \pm 0.06 \mathrm{e}$ & $3.6 \pm 0.08 \mathrm{e}$ & $9.5 \pm 0.10 \mathrm{e}$ \\
30 & 35 & $5.9 \pm 0.10 \mathrm{e}$ & $3.5 \pm 0.09 \mathrm{e}$ & $9.4 \pm 0.11 \mathrm{e}$ \\
33 & 22 & $6.7 \pm 0.14$ & & \\
35 & & & & \\
\end{tabular}

Means with the small letters within the same stage and different temperatures (13 to $33^{\circ} \mathrm{C}$ ) are not significantly different by Tukey's HSD test after one way ANOVA, $\mathrm{p}<0.05$. 
$9.5 \mathrm{~d}$ at $30{ }^{\circ} \mathrm{C}$. At all tested temperatures, pupal period was significantly shorter than the egg + larva stage period (Table 1).

Development rate of $C$. vestalis such as egg + larva, pupa and total development rate from egg to adult increased with temperature within temperature range of 13-33 ${ }^{\circ} \mathrm{C}$ but declined at $35{ }^{\circ} \mathrm{C}$ (Fig. 1). Significant linear relationships were indicated for the regression of individual development rate on temperature for each life stage period (Table 2; Fig. 1). From these equations, a lower developmental threshold $\left(\mathrm{T}_{0}\right)$ was estimated at 8.9, 10.1 and $9.4^{\circ} \mathrm{C}$ for egg + larvae, pupa and total immature stages, respectively. A thermal constant (DD) of 125.0,71.4 and 200.0 DD was estimated as the effective temperature sums for the development of the egg + larva, pupa and total development periods, respectively.

The non linear Logan model gave a good fit (R2 between 0.9162 and 0.9670 ) to the data sets of developmental rate for the range of temperature used (Fig. 1; Table 3). The optimal developmental temperatures estimated for egg + larva, pupa, egg to adult stages were $38.1,30.5$ and $31.3^{\circ} \mathrm{C}$, respectively. The upper limit temperatures for immature development of $C$. vestalis ranged between 35.0 and $38.2{ }^{\circ} \mathrm{C}$ (Table 3 ).

\section{DISCUSSION}

Our result is the first report on the effect different

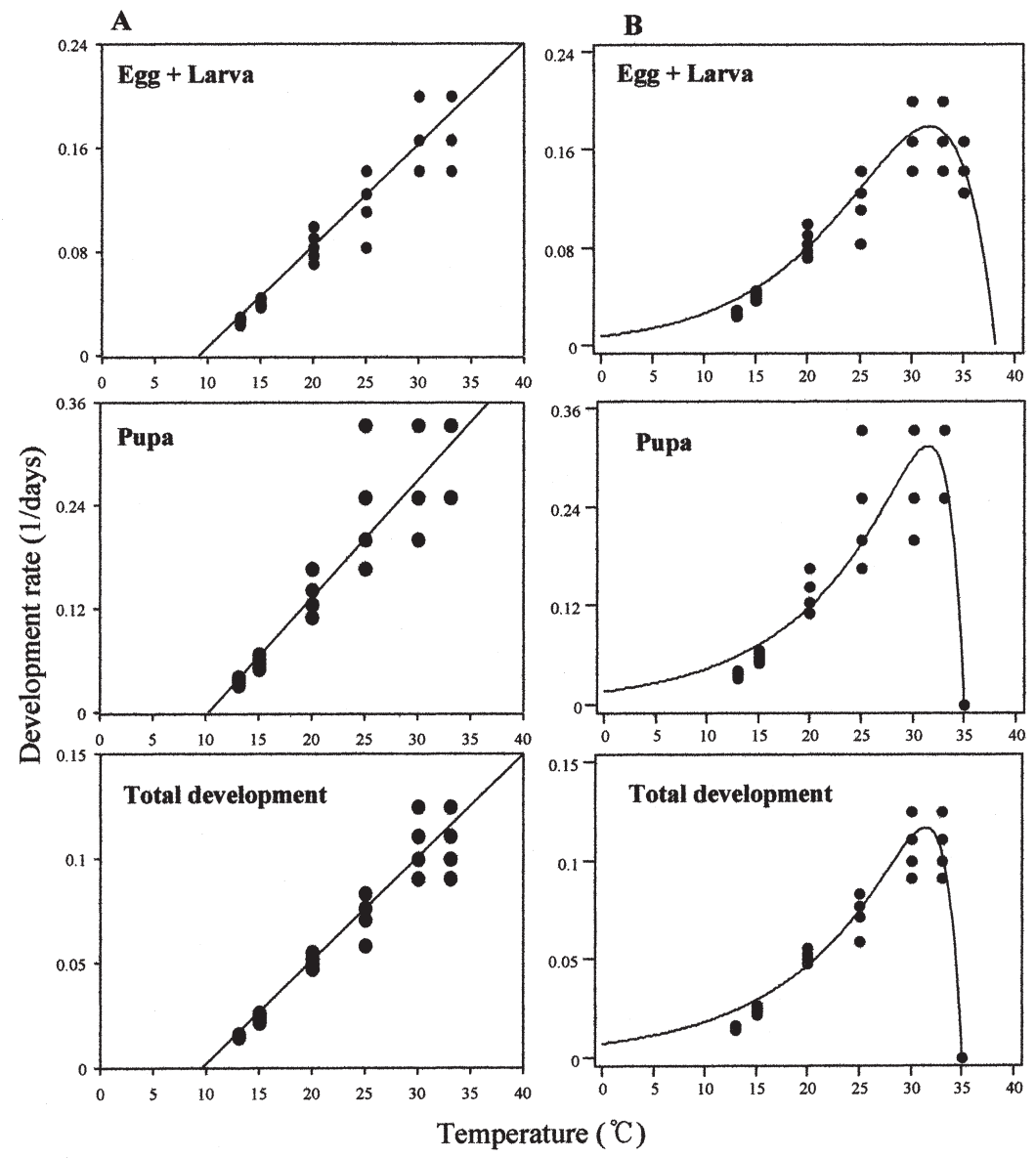

Fig. 1. Fitting of equations (A) Linear and (B) Logan-6 for the total biological cycle of $C$. vestalis on $P$. xylostella as a function of temperature.

Table 2. Linear regression equations of development rate vs temperature and estimated lower developmental threshold ( $\mathrm{T}_{0}$. ${ }^{\circ} \mathrm{C}$ ) and thermal constant (DD) for the immature stages of C. vestalis Myanmar strain ${ }^{a}$

\begin{tabular}{|c|c|c|c|c|c|c|c|c|}
\hline \multirow{2}{*}{ Stage } & \multirow{2}{*}{ Slope \pm SE } & \multirow{2}{*}{ Intercept $\pm \mathrm{SE}$} & \multicolumn{3}{|c|}{ ANOVA parameters } & \multirow{2}{*}{$r^{2}$} & \multirow{2}{*}{$\mathrm{T}_{0}$} & \multirow{2}{*}{$\mathrm{DD}$} \\
\hline & & & F & $\mathrm{df}$ & $\mathrm{P}$ & & & \\
\hline Egg-Pupa & $0.008 \pm 0.0001$ & $-0.071 \pm 0.003$ & 3960.6 & 1,241 & $<0.0001$ & 0.943 & 8.9 & 125 \\
\hline Pupa-Adult & $0.014 \pm 0.00003$ & $-0.141 \pm 0.007$ & 2188.8 & 1,241 & $<0.0001$ & 0.901 & 10.1 & 71.4 \\
\hline Total & $0.005 \pm 0.00006$ & $-0.047 \pm 0.002$ & 6232.9 & 1,241 & $<0.0001$ & 0.963 & 9.4 & 200 \\
\hline
\end{tabular}

${ }^{a}$ Data were obtained from experiments conducted at six constant temperatures $\left(13,15,20,25,30\right.$ and $\left.33^{\circ} \mathrm{C}\right)$ 
Table 3. Parameters of Logan equation, upper temperature thresholds, and optimum development temperature for immature stages of $C$. vestalis Myanmar strain ${ }^{\mathrm{a}}$

\begin{tabular}{lcccccc}
\hline Stage & P1 & P2 & P3 & $\mathrm{R}^{2}$ & $\begin{array}{c}\text { Upper threshold } \\
\left({ }^{\circ} \mathrm{C}\right)\end{array}$ & $\begin{array}{c}\text { Optimum } \\
\text { temperature }\left({ }^{\circ} \mathrm{C}\right)\end{array}$ \\
\hline Egg-Pupa & 0.1638 & 0.1555 & 0.1574 & 0.9505 & 38.2 & 31.8 \\
Pupa-Adult & 0.2153 & 0.1000 & 0.6132 & 0.9162 & 35.0 & 30.5 \\
Total & 0.0172 & 0.0944 & 0.0621 & 0.9670 & 35.0 & 31.3 \\
\hline
\end{tabular}

${ }^{a}$ Data were obtained from experiments conducted at seven constant temperatures $(13,15,20,25,30,33$ and $\left.35^{\circ} \mathrm{C}\right)$

temperatures on development of Myanmar strain of $C$. vestalis on $P$. xylostella. No data on development of Myanmar strain of $C$. vestalis on $P$. xylostella were previously available. The lower threshold temperature for total development of $C$. vestalis in this study $\left(9.4^{\circ} \mathrm{C}\right)$ is slightly higher than that of Nofemela (2004) $\left(8.14^{\circ} \mathrm{C}\right)$ for the South African strain, but is lower than that calculated by Lim (in Nofemela 2004) $\left(13.8^{\circ} \mathrm{C}\right)$ for the Malaysian strain of $C$. vestalis and $\left(11.0^{\circ} \mathrm{C}\right)$ for the Chinese strain (Shi and Liu, 1999). The thermal constant estimated from our data for total development (200.0 DD) was lower than estimated by Nofemela (2004) (217.39 DD) but higher than by Shi and Liu (1999) (169.28 DD). These differences could be difference of civestalis populations or difference of host reared on different food source, because thermal characteristics may vary between populations (Campbell et al., 1974; Lee and Elliott, 1998), and developmental stages (Honek and Kocourek, 1988), and with other ecological factors such as food source (Gilbert and Raworth, 1996). At all tested temperatures pupal period was shorter than the egg + larva period (Table 1). This finding is in agreement with (Kawaguchi and Tanaka, 1998; Shi et al., 2002; Nofemela, 2004) and for C. vestalis on DBM reared on cabbage (Htwe, unpublished).

Development rate was positively correlated with temperature at $13-33^{\circ} \mathrm{C}$. Some $C$. vestalis larvae reach to pupa stage but no pupae succeeded in completing development at $35^{\circ} \mathrm{C}$, indicating that this temperature falls out of development temperature range. Our findings on the effect of constant temperatures on development of $P$. xylostella as a host of $C$. vestalis showed that $P$. xylostella could not developed until adult at $35^{\circ} \mathrm{C}$, and this could be an evolutionary relationship between them. The linear model is widely used for calculating low temperature threshold and thermal constant in numerous studies (Dent and Walton, 1997; Roy et al., 2002; Kontodimas et al., 2004). But the weakness of the linear model are; the relationship holds only for a medium range of temperatures (Campbell et al., 1974; Gilbert et al., 1976) and the estimated threshold is an extrapolation of the linear portion of the relationship into a region where the relationship is unlikely to be linear (Jervis and Copland, 1996) thus lower developmental threshold and the thermal constant may be underestimated at temperatures close to the lower threshold (Howe, 1967). Although it has disadvantages the linear model has been used widely because it requires minimal data for formulation to calculate and apply easily and is the simplest method for estimation of the thermal constant (Worner, 1992).

We applied the nonlinear Logan model to study the adverse effect of extreme temperatures on developmental rate. It is one of the most commonly used models for description of temperature-dependent development of insects and other arthropods (Kontodimas et al., 2004). The biological interpretation of all fitted coefficients of the equation 6 is remarkable and should be regarded as a major advantage when evaluating this model (Logan $e t$ $a l .$, 1976). The model fit the data well and predicted the values for the upper temperature ranged between 35.0 and $38.2{ }^{\circ} \mathrm{C}$, and the optimum temperature ranged between 30.5 to $31.8^{\circ} \mathrm{C}$. The Logan model has certain advantages over linear regression, including good estimates of upper threshold and optimum temperature and a description of the nonlinear response to temperature.

Our study has provided the necessary information and mathematical description of the development rate of C. vestalis. Liu et al. (1995) suggested that rate functions derived from constant temperature can be used effectively to predict population development in the field. Information on thermal requirement of $C$. vestalis could be useful in selection of appropriate candidate for release under given climatic conditions for biological control of diamondback moth. Furthermore our findings may provide necessary information for biological control by augmentation and introduction program. For augmentative biological control timing is also important because the potential use of parasitoids or entomopathogenic nematode would require precise timing for success (Petit and Wietlisbach, 1993; Head et al., 2000). It will be valuable when this information used in association with other biological and ecological data for development and implementation of DBM management program.

\section{REFERENCES}

Abro, G. H., R. A. Soomro and T. S. Syed 1992 Biology and behavior of diamondback moth, Plutella xylostella (L.) Pakistan J. Zoo., 24: 7-10

Campbell, A., B. D. Frazer, N. Gilbert, A. P. Gutierrez and M. Mackauer 1974 Temperature requirements of some aphids and their parasites. Journal of Applied Ecology 11: 431-438

Dent, D. R. and M. P. Walton 1997 Methods in ecological and agricultural entomology. CAB International, Cambridge, United Kingdom 
Fitton, M. and A. Walker 1992 Hymenopterous parasitoids associated with diamondback moth: the taxonomic dilemma. In Management of Diamondback Moth and Other Crucifer Pests: Proceedings of the Second International Workshop. (N. S. Talekar ed.) pp. 225-232. Asian Vegetable Research and Development Center. Shanhua, Taiwan

Gilbert, N. A. P. Gutierrez, B. D. Frazer and R. E. Jones 1976 Ecological relationships. W. H. Freeman and Co., Reading, United Kingdom

Gilbert, N. and D. A. Raworth 1996 Insect and temperature, a general theory. Can. Entomol. 128: 1-13

Goodwin, S. 1979 Changes in numbers in the parasitoid complex associated with the diamondback moth, Plutella xylostella (L.) (Lepidoptera), in Victoria. Australian Journal of Zoology., 27: 981-989

Head, J., K. E. A. Walter and S. Langton 2000 The compatibility of the entomopathogenic nematode, Steinernema feltiae, and chemical insecticides for the control of the South Am. Leafminer, Liriomyza huidobrensis. BioControl., 45: 345-353

Honek, A. and F. Kocourek 1988 Thermal requirements for development of aphidophagous Coccinellidae (Coleoptera), Chrysopidae, Hemerobiidae (Neuroptera), and Syrphidae (Diptera): some general trends. Oecologia., 76: 455-460

Howe, R. W. 1967 Temperature effects on embryonic development in insects. Annu. Rev. Entomol. 10: 15-42

Jervis, M. A. and M. J. W. Copland 1996 The life cycle, pp. 63-161. In: M. A. Jervis and N. Kidd (eds.), Insect natural enemies-practical approaches to their study and evaluation. Chapman \& Hall, London, United Kingdom

Kawaguchi, M. and T. Tanaka 1999 Biological characteristics of a larval endoparasitoid, Cotesia plutellae (Hymenoptera: Braconidae): Host stage preference, subsequent sex ratio of progeny and mate location of males. Appl. Entomol. Zool. 34: 213-221

Kontodimas, D. C., P. A. Eliopoulos, G. J. Stathas and L. P. Economou 2004 Comparative temperature-dependent development of Nephus includens (Kirsch) and Nephus bisignatus (Boheman) (Coleoptera: Coccinellidae) preying on Planococcus citri (Risso) (Homoptera: Pseudococcidae): evaluation of a linear and various nonlinear models using specific criteria. Environ. Entomol. 33: 1-11

Lee, J. H. and N. C. Elliott 1998 Comparison of developmental responses to temperature in Aphelinus asychis (Walker) from two different geographic regions. Southwest Entomologist, 23: $77-82$

Lim, G. S. 1986 Biological control of diamondback moth. Diamondback moth Management: Proceedings of the First International Workshop (eds. N. S. Talekar \& T. D. Griggs), pp. 159-171. March 11-15, Shanhua, Taiwan, China

Liu, S. S., F. Z. Chen, and M. P. Zalucki 2002 Development and survival of the diamondback moth (Lepidoptera: Plutellidae) at constant and alternating temperatures. Environ. Entomol., 31: 221D231

Liu, S. S., G. M. Zhang and J. Zhu 1995 Influence of temperature variations on rate of development in insects: analysis of case studies from entomological literature. Ann. Entomol. Soc. Am., 88: $107-119$

Logan, J. A., D. J. Wollkind, S. C. Hoyt and L. K. Tanigoshi 1976 An analytic model for description of temperature dependent rate phenomena in arthropods. Environmental Entomology., 5: $1133-40$

Maung, N. 2002 Potential use of F1 sterility and the parasitoid, Cotesia plutellae, to control diamondback moth, Plutella xylostella, in Myanmar, pp. 109-112. In Proceedings: Evaluation of Lepidoptera Population Suppression by Radiation Induced Sterility. FAO/IAEA Final Research. Coordination Meeting, 28 May-2 June 1998, Penang, Malaysia. TECDOC 1283. IAEA, Vienna, Australia

Maung, N. and H. Morris 2001 Rearing of Cabbage Diamondback Moth (DBM) on various foods it's storage, Parasitization and gamma radiation tests in laboratory (DBM-SIT) (1998-1999), pp. 63-82. In Journal of Agricultural, Forestry, Livestock and
Fishery Sciences, Yangon, Myanmar

Morris, H. and D. F. Waterhouse 2001 The distribution and important of arthropod pest and weeds of agriculture in Myanmar. ACIAR Monograph., 67: 73 pp

Noda, T., S. Miyai and S. Yamada 1996 Larval and pupal parasitoids of diamondback moth, Plutella xylostella (L) in cabbage fields in Morioka, Japan. Japanese J. Appl. Entomol. Zool. 40 164-167

Nofemela, S. R. 2004 Studies on parasitoids of the diamondback moth, Plutella xylostella (L.) (Lepidoptera: Plutellidae), in South Africa. MS Thesis, Rhodes University, Grahamstown, South Africa

Obrycki, J. J and T. J. Kring 1998 Predaceous Coccinellidae in biological control. Annu. Rev. Entomol. 43: 295-321

Petitt, F. L. and D. O. Wietlisbach 1993 Effects of host instar and size on parasitization efficiency and life history parameters of Opius dissitus. Entomol. Exp. Appl., 66: 227-236

Reddy, G. V. P., E. Tabone and M. T. Smith (2004) Mediation of host selection and oviposition behavior in the diamondback moth Plutella xylostella and its predator Chrysoperla carnea by chemical cues from cole crops. Biol. Cont. 29: 270-277

Roy, M., J. Brodeur and C. Cloutier 2002 Relationship between temperature and development rate of Stethorus punctillum (Coleoptera: Coccinellidae) and its prey Tetranychus mcdanieli (Acarina: Tetranychidae). Environ. Entomol., 31 $177-187$

Sarfraz, M. and B. A. Keddie 2005 Conserving the efficacy of insecticides against Plutella xylostella (L.) (Lep., Plutellidae) Journal of Applied Entomology, 129: 149-157

Sarfraz, M., L. M. Dosdall and B. A Keddie 2006 Diamondback moth-host plant interactions: Implications for pest management. Crop Protection, 25: 625-639

SAS Institute. 1998 Stat View 5.0. J. SAS Institute, Cary, NC

Shaw, M. R. 2003 Revised synonymy in the genus Cotesia (Hymenoptera: Braconidae: Microgastrinae): the identity of Microgaster vestalis Haliday, 1834, as a senior synonym of Apanteles plutellae Kurdjumov, 1912. Entomol. Gaz $\mathbf{5 4}$ 187-189

Shelton, A. M., J. A. Wyman, N. L. Cushing, K. Apfelbeck, T. J. Dennehy, S. E. R. Mahr and S. D. Eigenbrode 1993 Insecticide resistance of diamondback moth (Lepidoptera: Plutellidae) in North America. J. Econ. Entomol. 86: 11-19

Shelton, A. M. 2004. Management of the diamondback moth: déjà vu all over again? In: Endersby, N. M., Ridland, P. M. (Eds.), The Management of Diamondback Moth and Other Crucifer Pests Proceedings of the Fourth International Workshop, 26-29 November 2001. Department of Natural Resources and Environment, Melbourne, Australia, pp. 3-8

Shi, Z. and S. Liu 1999 Influence of temperature on the development, survival and reproduction of Cotesia plutellae Kudj., a larval parasite of Plutella xylostella. Acta Phytophylacica Sinica., 26: $142-146$

Shi, Z., S. Liu and Y. Li 2002 Cotesia plutellae parasitizing Plutella xylostella: Host age dependent parasitism and its effect on host development and food consumption. BioControl. 47: 499-511

Shirai, Y. 2000 Temperature tolerance of the diamondback moth, Plutella xylostella (Lepidoptera: Yponomeutidae) in tropical and temperate regions of Asia. Bulletin of Entomological Research 90: 357-364

Talekar, N. S. and A. M. Shelton 1993 Biology, ecology and management of the diamondback moth. Annv. Rev. Entomol. 38: 275-301

Talekar, N. S. and J. C. Yang 1993 Influence of crucifer cropping system on the parasitism of Plutella xylostella (Lep., Yponomeutidae) by Cotesia plutellae (Hym., Braconidae) and Diadegma semiclausum (Hym., Ichneumonidae). Entomophaga 38: 541-550

Thwin, M. N. 2001 Country Report from Myanmar in Report of the twenty-second session of the Asia and Pacific Protection Comission, 17 to 21 September 2001, Ho Chi Minh, Viet Nam, RAP, Publication 2001/24 
Verkerk, R. H. J. and D. J. Wright 1997 Field-based studies with the diamondback moth tritrophic system in Cameron Highlands of Malaysia: implications for pest management International Journal of Pest Management., 43: 27-33

Waterhouse, D. F. and K. R. Norris 1987
Pacific prospects. Melbourne, Inkata Press

Worner, S. P. 1992 Performance of phenological models under variable temperature regimes: consequences of the Kaufman or rate summation effect. Environ. Entomol. 21: 689-699 